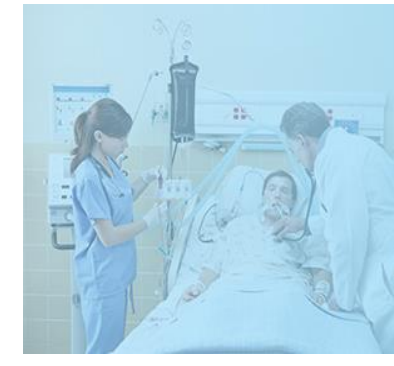

E-ISSN: $2663-2268$

P-ISSN: 2663-225X

IJARMSN 2020; 2(2): 08-15

www.surgicalnursingjournal.com

Received: 07-05-2020

Accepted: 10-06-2020

Priyanka Sharma

M.Sc. Medical Surgical

Nursing, Neta Ji Subhash

College of Nursing, Palampur,

Himachal Pradesh, India

\section{Deepika Thakur}

Assistant Professor,

Department of Medical

Surgical Nursing, Neta Ji

Subhash College of Nursing,

Palampur, Himachal Pradesh,

India
Corresponding Author:

Priyanka Sharma

M.Sc. Medical Surgical

Nursing, Neta Ji Subhash

College of Nursing, Palampur,

Himachal Pradesh, India

International Journal of Advance Research in Medical Surgical Nursing

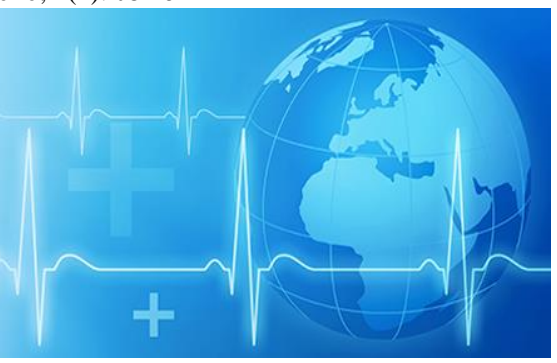

\section{A descriptive study to assess the health-related quality of life among diabetic patients visiting medical out- patient department of selected health care facilities at District Mandi (Himachal Pradesh)}

\author{
Priyanka Sharma and Deepika Thakur \\ DOI: https://doi.org/10.33545/surgicalnursing.2020.v2.i2a.38
}

\begin{abstract}
Diabetes Mellitus is a chronic lifelong disease one has to live with. The quality of life assessment is considered an important measure of outcome in long-term illness and management.

Objective: The objective of the study to assess the health-related quality of life among diabetic patients with determination of relationship between the domains and to determine the association between socio-demographic variables and health related quality of life.

Material and method: A quantitative research approach and descriptive research design was adopted to conduct study. The non- probability convenience sampling technique was used to select 150 diabetic patients visiting medical out-patient department of selected health care facilities. Modified quality of life instrument was used to assess the health-related quality of life among diabetic patients.

Result: All the study participants had good health related quality of life with mean percentage $(68.345 \%)$, overall mean and SD score of health-related quality of life among subjects i.e. mean score \pm S.D $136.69 \pm 26.343$. As the result of $\mathrm{chi}^{2}$ test, gender, age (in years), education, monthly income, dietary habit, physical activity, treatment had significant association $(\mathrm{p} \leq 0.05)$ with health-related quality of life.

Conclusion: The study concluded that majority of the subjects (diabetic patients) had good health related quality of life. Role limitation had positive relationship with all the domains of health-related quality of life. Gender, age (in years), education, monthly income, dietary habit, physical activity and treatment were significantly associated with health-related quality of life.
\end{abstract}

Keywords: Quality of life, diabetes mellitus, diabetic patient

\section{Introduction}

Diabetes Mellitus' is a disease known from ancient times. The term diabetes mellitus is derived from a Greek word which means to go through or a siphon and the word Mellitus is derived from a Latin word Me (honey) describes the sweet odor of the urine. It is also called the disease of prosperities. Non-communicable diseases associated with changes in lifestyle and diet has become a major public health problem in both the developed and developing countries. Diabetes is at the forefront of non-communicable diseases ${ }^{[1]}$.

According to the World Health Organization (WHO), India had 69.2 million people living with diabetes in 2015 and 98 million people in India may have type II diabetes by 2030. As per the WHO global current report, about 422 million adults have diabetes, 1.6 million deaths are directly attributed to diabetes each year and 1 in 3 adults aged over 18 years is overweighed and 1 in 10 is obese. Diabetes is a growing challenge in India with estimated $8.7 \%$ diabetic population in the age group of 20 and 70 years. In 2016, an estimated 1.6 million deaths were directly caused by diabetes. Diabetes is a major cause of blindness, kidney failure, heart attacks, stroke and lower limb amputation ${ }^{[2,3]}$.

According to international diabetes federation report of 2017, Diabetes is a huge and growing burden. 425 million people have diabetes in the world and 82 million people in the South east Asia Region; by 2045 this will rise to 151 million. There were over approximately 7.2 million cases of diabetes in India in 2017 with prevalence rate of $8.8 \%$. Most of these cases are type 2 diabetes, which is largely preventable through regular physical activity, a healthy and balanced diet, and the promotion of healthy living environments. About 279 million people are living in urban area and 146 million people are living in rural area. 
Early detection and timely management of diabetes can prevent many diseases ${ }^{[4]}$.

It is not possible for anyone to visit the doctor or hospital over now and then for rest of life. Therefore, it is important that the patient learns how to manage their disease themselves as much as possible. Diabetes can affect the life of those who suffer from it in many ways: emotionally, physically, socially and financially ${ }^{[5]}$.

Quality of life (QOL) is defined by World Health Organization as "individuals' perceptions of their position in life in the context of the culture and value systems in which they live and in relation to their goals, expectations, standards and concerns". It is a broad ranging concept affected in a complex way by the person's physical health, psychological state, level of independence, social relationships, personal beliefs and their relationship to salient features of their environment ${ }^{[6]}$. Conventional outcome assessment for diabetes relies on laboratory indicators, primarily on haemoglobin A1c (HbA1c) and complications of diseases. The exclusive reliance on clinical outcomes, however, does not necessarily reflect patients' perceptions of their heath. Therefore, health-related quality of life (HRQOL) is increasingly used as an outcome indicator alongside traditional biomedical measures. ${ }^{7}$

\subsection{Need of the study}

As a major epidemic of the $21^{\text {st }}$ century diabetes mellitus is a threat to public health and is associated with increased physical, psychological and social morbidity and mortality if left untreated. According to WHO estimates India will be the global capital of diabetes by 2025 , accounting for 57.2 million diabetics. Worsening the situation is the fact that diabetes affects the economically productive age-group (4565 years) in developing countries ${ }^{[3,8]}$.

Diabetes mellitus permanently changes a patient's life. The Quality of life (QoL) is very important because it is a powerful tool to predict an individual's capacity to manage the disease and maintain long-term health and wellbeing ${ }^{[9]}$. Quality of life is an important aspect in diabetes because poor quality of life leads to diminished self-care, which in turn leads to worsened glycemic control, increased risks for complications ${ }^{[10]}$. India has become the capital and turned out to increase in the mortality rate. Although most of the modern drugs are medicated but due to some adverse effects it still remains a big question mark among researchers. Health care providers focus on only to control hyperglycaemia, lack of concentration on overall quality of life of diabetic patients ${ }^{[11]}$.

One goal of the measurement of quality of life is to have objective evaluations of how and how much the disease influences patient's life and how patients cope with it. The evaluation may be useful as a baseline and outcome measures and should provide framework to determine the impact of any change on patient's quality of life. The Quality of life (QoL) is very important because it is a powerful tool to predict an individual's capacity to manage the disease and maintain long-term health and wellbeing. Routine assessment of Quality of life (QoL) as a part of clinical practice has the potential to improve communication between the patient and the health care provider, identify frequently overlooked problems, assess the problems, and evaluate the effect of therapeutic efforts at the individual patient's level ${ }^{[8]}$. The purpose of present study is to throw a light on various domains of quality of life of diabetic patient. Understanding these domains that contribute quality of life among people with diabetes may help the health care professionals to provide holistic care

\subsection{Objectives}

1. To assess the health-related quality of life among diabetic patients visiting medical out-patient department of selected health care facilities at District Mandi, Himachal Pradesh.

2. To determine the relationship between the domains of health-related quality of life among diabetic patients.

3. To determine the association of level of health-related quality of life among diabetic patients with the selected socio-demographic variables.

\subsection{Conceptual framework}

Theoretical framework used for the present study is based on the health promotion model. The health promotion model (HPM) proposed by Nola J Pender (1982, revised, 1996) ${ }^{[12]}$. Health promotion means give awareness to people to choose healthy lifestyle and encouraging them to do things themselves. To achieve this one should focus on the health promoting strategies, such as daily physical activity, health nutrition, stress reduction or to avoid the use of tobacco, alcohol or drugs.

\section{Components of the model}

- Individual characteristics and behavior

- Behavior specific cognitions and affect

- Behavior outcome- health promoting behavior

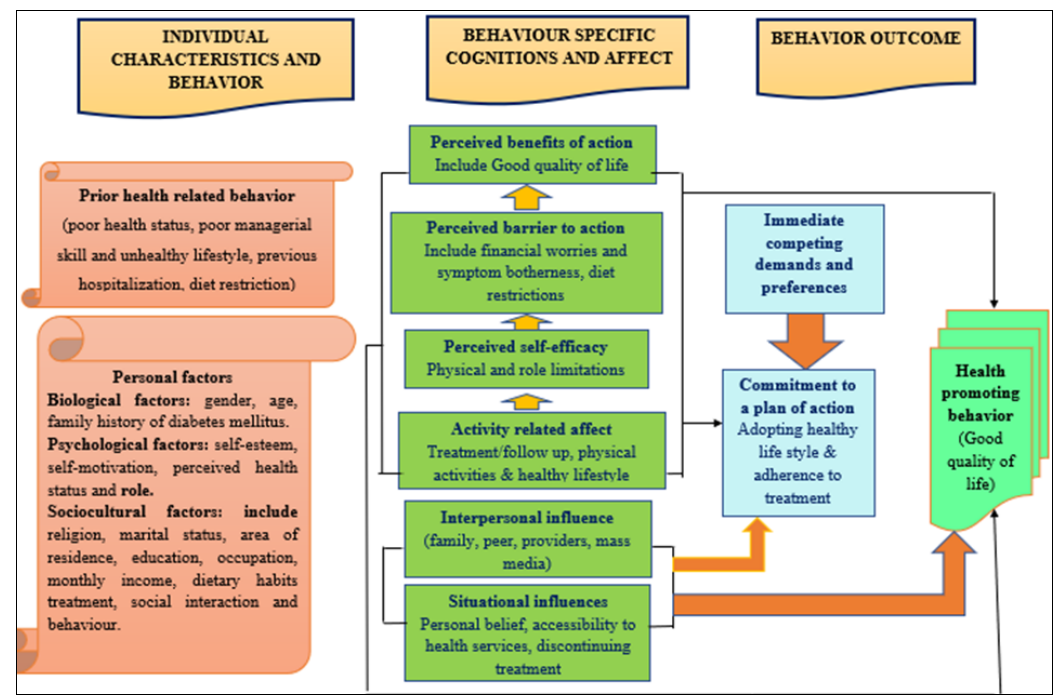

Fig 1: Health promotion by nola 


\section{Material and methods}

2.1 Research approach and design: To accomplish the objective of the present study a quantitative approach, a Non-Experimental Descriptive research design was used to assess the health-related quality of life among diabetic patients.

2.2 Research setting: The study was conducted among diabetic patients visiting at medical out-patient department of Sri Lal Bahadur Shastri medical college and hospital NerChowk, District Mandi, Sri Harihar Hospital and Research Centre, Gutkar, District. Mandi, Civil Hospital Sundernagar, District Mandi and Malhotra Trauma Centre, Ner-Chowk, District Mandi himachal Pradesh.

2.3 Sample and sampling technique: Sample consists of 150 diabetic patients under selected settings. Nonprobability purposive sampling technique was adopted for the study.

\subsection{Criteria for sample selection Inclusion criteria}

- Diabetic patients who were above 30 years.

- Both male and female patients.

- Diabetic patients available at the time of study.

- $\quad$ Patients diagnosed with Type 2 diabetes mellitus.

- Diabetic patients who can read and write Hindi or English.

- Diabetic patients who were willing to participate in study.

\section{Exclusion criteria}

- Patients with gestational diabetes.

- $\quad$ Patient with Type 1 Diabetes mellitus.

- Patients who were not willing to participate.

- Any other chronic illness which requires the patient to be admitted in the hospital for more than two weeks in the past one year.

\subsection{Description of tool}

Section I: Sociodemographic variables- It consists of fourteen items. It includes gender, age (in years), religion, marital status, area of residence, education, occupational status, monthly family income (in ₹), type of family, family history of diabetes mellitus, dietary habit, physical activity and treatment.

Section II: Modified Quality of life instrument for Indian Diabetic Patients- it is the modified version of the tool given by Jitender Nagpal ${ }^{[11]}$ personal belief domain was added and modification were done in each domain. It consists of 40 items which is further divided into nine domains which includes, general health, physical limitation, symptom botherness, Role limitation, Psychosocial satisfaction, economic worries, diet satisfaction, Treatment satisfaction/ follow up and personal beliefs.

2.6 Validity: Modified quality of life instrument for Indian diabetic patient was given to 10 experts of nursing field and their suggestion were expected and incorporated. The content validity of the tool was done by opinion of experts.
Initially in section 1 , there were 15 variables. In section 2 , 42 items were included in Modified quality of life instrument for Indian diabetic patient. The final tool consists of 14 variables in section 1 and 40 items in section 2. The tool was then translated in Hindi and retranslated in English and the tool was found to be consistent.

Table 1: Showing Criteria for assessing the overall health related quality of life

\begin{tabular}{|c|c|c|c|}
\hline S. No & HRQOL & Score & Percentage (\%) \\
\hline 1 & Good & $\geq 135$ & $\geq 67$ \\
\hline 2 & Average & $68-134$ & $34-66$ \\
\hline 3 & Poor & $\leq 67$ & $\leq 33$ \\
\hline
\end{tabular}

Minimum score: 40

Maximum score: 200

2.7 Pilot study: The pilot study was conducted on 29/12/2018 \& 30/12/2018 at Karan Hospital, Palampur District. Kangra (Himachal Pradesh) in order to test the feasibility and time required. Pilot study was conducted on the $10 \%$ of total population. The data was collected by administering modified quality of life instrument for Indian diabetic patient. The findings of the study revealed that study is feasible. Pilot study was done to check the items for their clarity and relevance.

2.8 Reliability: Split half method was used to check the internal consistency of modified quality of life instrument for Indian diabetic patient and the value of Karl Pearson correlation coefficient found (0.76), hence, the tool was reliable.

2.9 Data collection procedure: The main study was conducted in the month of February 2019 and March 2019 at selected health care facilities at district Mandi, Himachal Pradesh. The purpose of data collection was explained to the sample. Prior to data collection written consent was taken from the diabetic patients. By using non- probability convenience sampling technique 150 diabetic patients from medical outpatient departments of selected health care facilities were selected. Modified quality of instrument for Indian diabetic patient was administered. Coding sheet was prepared for data analysis.

2.10 Ethical consideration: Prior to the data collection permission was obtained from the concerned authorities to conduct the study. Written consent was obtained from the diabetic patients visiting medical outpatient department of selected health care facilities at district Mandi (Himachal Pradesh). The study subjects were assured that information collected from them was confidential.

\section{Plan of data analysis}

Data analysis and interpretation of data was done according to the objectives of the study. Analysis was done by using descriptive and inferential statistics. Assessment of level of health-related quality of life among diabetic patients was calculated by mean Percentage. Relationship among the domains of health-related quality of life was calculated by correlation coefficient method. Chi square test was used to determine the association between socio-demographic variables and health related quality of life among diabetic patients. Graphical presentation has been used to depict the findings. 


\section{Analysis and interpretation of data}

Section 1: Description of selected variables

Section 2: Frequency, percentage, median, standard deviation, standard error of mean and range of domains of health-related quality of life.

Section 3: Correlation between the domains of healthrelated quality of life.
Section 4: Association between socio-demographic variables and health related quality of life among diabetic patients

\section{SECTION 1}

Description of Selected Socio-demographic Variables TABLE-2

Table 2: Showing the frequency and percentage distribution of socio-demographic variablesN=150

\begin{tabular}{|c|c|c|c|}
\hline Sr. no. & Socio-demographic variables & Frequency (f) & Percentage $(\%)$ \\
\hline \multirow{3}{*}{1.} & \multicolumn{3}{|c|}{ Gender } \\
\hline & 1.1 Male & 77 & 51.3 \\
\hline & 1.2 Female & 73 & 48.7 \\
\hline \multirow{5}{*}{2.} & \multicolumn{3}{|c|}{ Age (in years) } \\
\hline & $2.1 \quad 31-40$ & 13 & 8.7 \\
\hline & $2.2 \quad 41-50$ & 36 & 24 \\
\hline & $2.3 \quad 51-60$ & 40 & 26.7 \\
\hline & $2.4 \quad 61$ and above & 61 & 40.7 \\
\hline \multirow{4}{*}{3.} & \multicolumn{3}{|c|}{ Religion } \\
\hline & 3.1 Hindu & 144 & 96 \\
\hline & 3.2 Sikh & 02 & 1.3 \\
\hline & 3.3 Muslim & 04 & 2.7 \\
\hline \multirow{5}{*}{4.} & \multicolumn{3}{|c|}{ Marital status } \\
\hline & 4.1 Unmarried & 04 & 2.7 \\
\hline & 4.2 Married & 125 & 83.3 \\
\hline & 4.3 Divorced & 01 & 0.7 \\
\hline & 4.4 Widow/widower & 20 & 13.3 \\
\hline \multirow{3}{*}{5.} & \multicolumn{3}{|c|}{ Area of residence } \\
\hline & 5.1 Rural & 111 & 74 \\
\hline & 5.2 Urban & 39 & 26 \\
\hline \multirow{5}{*}{6.} & \multicolumn{3}{|c|}{ Education } \\
\hline & 6.1 Non-formal education & 23 & 15.3 \\
\hline & 6.2 Primary & 32 & 21.3 \\
\hline & 6.3 Higher secondary & 53 & 35.3 \\
\hline & 6.4 Graduate and above & 42 & 28 \\
\hline \multirow{6}{*}{7.} & \multicolumn{3}{|c|}{ Occupation status } \\
\hline & 7.1 Government employee & 20 & 13.3 \\
\hline & 7.2 Self employed & 26 & 17.3 \\
\hline & 7.3 Private employee & 15 & 10 \\
\hline & 7.4 Home maker & 65 & 43.3 \\
\hline & 7.5 Retired & 24 & 16 \\
\hline \multirow{5}{*}{8.} & \multicolumn{3}{|c|}{ Monthly income (in ₹) } \\
\hline & $8.1 \leq 10,000 /-$ & 23 & 15.3 \\
\hline & $8.210,001-20,000 /-$ & 45 & 30 \\
\hline & $8.2 \quad 20,001-30,000 /-$ & 24 & 16 \\
\hline & $8.3 \geq 30,001 /-$ & 58 & 38.7 \\
\hline \multirow{3}{*}{9.} & \multicolumn{3}{|c|}{ Type of family } \\
\hline & 9.1 Joint family & 103 & 68.7 \\
\hline & 9.2 Nuclear family & 47 & 31.3 \\
\hline \multirow{4}{*}{10.} & \multicolumn{3}{|c|}{ Family history of diabetes mellitus } \\
\hline & $10.1 \mathrm{No}$ & 88 & 58.7 \\
\hline & 10.2 Maternal & 35 & 23.3 \\
\hline & 10.3 Paternal & 27 & 18 \\
\hline \multirow{3}{*}{11.} & & labit & \\
\hline & 11.1 Vegetarian & 101 & 67.3 \\
\hline & 11.2 Non- vegetarian & 49 & 32.7 \\
\hline & & ctivity & \\
\hline 12 & 12.1 Light & 96 & 64 \\
\hline 12. & 12.2 Moderate & 47 & 31.3 \\
\hline & 12.3 Heavy & 07 & 4.7 \\
\hline 13. & Do you h & ther disease? & \\
\hline
\end{tabular}




\begin{tabular}{|c|c|c|c|}
\hline \multirow{4}{*}{} & 13.1 Yes & 76 & 50.7 \\
\cline { 2 - 4 } & 13.2 No & 74 & 49.3 \\
\hline \multirow{4}{*}{14.} & \multicolumn{2}{|c|}{ Treatment } \\
\cline { 2 - 4 } & 14.1 Oral hypoglycemic drugs & 132 & 88.0 \\
\cline { 2 - 4 } & 14.2 Insulin & 07 & 4.7 \\
\cline { 2 - 4 } & 14.3 Diet only & 09 & 6.0 \\
\cline { 2 - 4 } & 14.4 Others & 02 & 1.3 \\
\hline
\end{tabular}

Table 2 describes the socio-demographic variable and the results revealed that out of 150 samples, nearly half of the subjects, $(51.3 \%)$ were male, $(40.7 \%)$ in age group of 61 and above, (96\%) were Hindu, $(83.3 \%)$ were married, $(74 \%)$ were from rural area, $(35.3 \%)$ had secondary education, $(43.3 \%)$ were home maker, $(38.7 \%)$ had monthly income $\geq 30,001 /-,(68.7 \%)$ were from joint family, (58.7\%) had no family history of diabetes mellitus, $(67.3 \%)$ were vegetarian, (64\%) had light physical activity, (50.7\%) had other disease with diabetes mellitus, $(88 \%)$ were on oral hypoglycemic drugs.

Section 2

Frequency, Percentage, Median, Range, Standard Deviation, Standard Error of Mean of Domains of Health-Related Quality of Life TABLE 3

Table 3: Showing mean, mean percentage, median, range, standard deviation, standard error of mean of following domains $\mathrm{N}=150$

\begin{tabular}{|c|c|c|c|c|c|c|}
\hline Domain of Health-related Quality of life & Mean & Mean \% & Median & Range & SD & S.E. Mean \\
\hline General health & 11.77 & 58.85 & 12.00 & 16 & 3.666 & .299 \\
\hline Physical limitation & 17.42 & 69.68 & 18.50 & 20 & 5.331 & .435 \\
\hline Symptom botherness & 9.75 & 65.0 & 10.00 & 12 & 2.807 & .229 \\
\hline Role limitation & 19.64 & 65.46 & 21.00 & 24 & 6.005 & .490 \\
\hline Psychosocial satisfaction & 25.90 & 74.0 & 27.00 & 24 & 5.725 & .467 \\
\hline Economic worries & 18.77 & 75.08 & 20.00 & 19 & 4.416 & .361 \\
\hline Diet satisfaction & 8.38 & 55.86 & 9.00 & 12 & 2.616 & .214 \\
\hline Treatment Satisfaction/follow up & 13.95 & 69.75 & 15.00 & 16 & 3.345 & .273 \\
\hline Personal beliefs & 11.09 & 79.33 & 12.00 & 12 & 2.817 & .230 \\
\hline Overall health related quality of life & 136.69 & 68.34 & 141.50 & 122 & 26.34 & 2.151 \\
\hline
\end{tabular}

Table 3 revealed that the overall mean and SD score of health-related quality of life among subjects i.e. mean score \pm S.D $136.69 \pm 26.343$. The domain wise mean percentage of health-related quality of life score for general health is (58.85\%), Physical limitation (69.68\%), symptom botherness (65.0\%), Role limitation (65.46\%), Psychosocial satisfaction $(74.0 \%)$, economic worries $(75.08 \%)$, Diet satisfaction $(55.86 \%)$, treatment satisfaction/ follow up $(69.75 \%)$, personal beliefs $(79.33 \%)$ and overall health related quality of life with the mean percentage $(68.345 \%)$. TABLE 4

Table 4: Showing frequency and percentage distribution of overall health related quality of life among diabetic patients $\mathrm{N}=150$

\begin{tabular}{|c|c|c|c|}
\hline S. No & HRQOL & Frequency (n=150) & Percentage (\%) \\
\hline 1 & Good & 90 & 60 \\
\hline 2 & Average & 59 & 39.3 \\
\hline 3 & Poor & 01 & 0.7 \\
\hline
\end{tabular}

Table 4 shows frequency and percentage distribution of overall health related quality of life in which the most of subjects, (60\%) had good quality of life, (39.3\%) had average quality of life whereas only $(0.7 \%)$ had poor quality of life. Thus, it is inferred that more than half of the subjects have good health related quality of life.

Section 3

Correlation between the domains of health-related quality of life of diabetic patient Table 5

Table 5: Showing inter- relation matrix showing relationship between various domains health-related quality of life.

\begin{tabular}{|c|c|c|c|c|c|c|c|c|c|c|}
\hline Domain & $\mathbf{r}$ & $\begin{array}{c}\text { General } \\
\text { Health }\end{array}$ & $\begin{array}{l}\text { Physical } \\
\text { Limitation }\end{array}$ & $\begin{array}{l}\text { Symptom } \\
\text { Botherness }\end{array}$ & $\begin{array}{c}\text { Role } \\
\text { Limitation }\end{array}$ & $\begin{array}{l}\text { Psychosocial } \\
\text { satisfaction }\end{array}$ & $\begin{array}{c}\text { Economic } \\
\text { worries }\end{array}$ & $\begin{array}{c}\text { Dietary } \\
\text { satisfaction }\end{array}$ & $\begin{array}{l}\text { Treatment } \\
\text { satisfaction/ } \\
\text { follow up }\end{array}$ & $\begin{array}{c}\text { Personal } \\
\text { beliefs }\end{array}$ \\
\hline General Health & $\mathrm{r} \mid$ & 1 & & \multirow{5}{*}{1} & & & & & & \\
\hline Physical & $\mathrm{r}$ & .72 & \multirow{2}{*}{1} & & & & & & & \\
\hline Limitation & $\mathrm{p}$ & $.00^{*}$ & & & & & & & & \\
\hline Symptom & $\mathrm{r}$ & .31 & .30 & & & & & & & \\
\hline Botherness & $\mathrm{p}$ & $.00^{*}$ & $.00^{*}$ & & & & & & & \\
\hline \multirow{2}{*}{ Role Limitation } & $\mathrm{r}$ & .71 & .71 & .35 & \multirow{2}{*}{1} & & & & & \\
\hline & $\mathrm{p}$ & $.00^{*}$ & $.00^{*}$ & $.00^{*}$ & & & & & & \\
\hline \multirow{2}{*}{$\begin{array}{c}\text { Psychosocial } \\
\text { satisfaction }\end{array}$} & $\mathrm{r}$ & .66 & .66 & .34 & .73 & \multirow{2}{*}{. } & & & & \\
\hline & $\mathrm{p}$ & $.00^{*}$ & $.00^{*}$ & $.00^{*}$ & $.00^{*}$ & & & & & \\
\hline Economic & $\mathrm{r}$ & .43 & .40 & .10 & .40 & .46 & 1 & & & \\
\hline
\end{tabular}




\begin{tabular}{|c|c|c|c|c|c|c|c|c|c|c|}
\hline worries & $\mathrm{p}$ & $.00^{*}$ & $.00^{*}$ & .19 & $.00^{*}$ & $.00^{*}$ & & \multirow{3}{*}{1} & & \\
\hline \multirow{2}{*}{$\begin{array}{c}\text { Dietary } \\
\text { satisfaction }\end{array}$} & $\mathrm{r}$ & .11 & .15 & .02 & .20 & .10 & .06 & & & \\
\hline & $\mathrm{p}$ & .16 & .06 & .78 & $.01^{*}$ & .18 & .44 & & & \\
\hline \multirow{2}{*}{\multicolumn{2}{|c|}{$\begin{array}{l}\text { Treatment } \\
\text { satisfaction/ } \\
\text { follow up }\end{array}$}} & .45 & .50 & .12 & .44 & .56 & .42 & .19 & \multirow[b]{2}{*}{1} & \\
\hline & $\mathrm{p}$ & $.00^{*}$ & $.00^{*}$ & .11 & $.00^{*}$ & $.00^{*}$ & $.00^{*}$ & $.01^{*}$ & & \\
\hline \multirow{2}{*}{ Personal beliefs } & $\mathrm{R}$ & .50 & .52 & .19 & .44 & .58 & .36 & -.00 & .53 & \multirow{2}{*}{1} \\
\hline & $\mathrm{p}$ & $.00^{*}$ & $.00^{*}$ & $.01^{*}$ & $.00^{*}$ & $.00^{*}$ & $.00^{*}$ & .91 & $.00^{*}$ & \\
\hline
\end{tabular}

$\mathrm{r}=$ coefficient correlation

$*=p($ level of significance) $: \leq 0.05$

Table 5 showing inter- relation matrix showing relationship between various domains health-related quality of life by using Pearson coefficient correlation. The relationship of role limitation with general health, physical limitation, symptom botherness, psychosocial satisfaction, economic worries, dietary satisfaction, treatment satisfaction/ follow up and personal belief was found weak positive $(\mathrm{p} \leq 0.05)$.
Hence, Role limitation shows a positive relationship with all the domains of health-related quality of life.

\section{Section 4}

Association of Level of Health-Related Quality of Life among Diabetic Patients with the Selected SocioDemographic Variables Table 6

Table 6: Showing association of level of health-related quality of life among diabetic patients with the selected socio-demographic variables. $\mathrm{N}=150$

\begin{tabular}{|c|c|c|c|c|c|c|c|}
\hline Sr. no. & Socio-demographic variables & Poor & Average & Good & $\begin{array}{c}\text { Chi }^{\mathbf{2}} \\
\left(\chi^{2}\right)\end{array}$ & df & p value \\
\hline \multirow{3}{*}{1.} & Gender: & & & & 9.15 & 02 & $.01^{*}$ \\
\hline & 1.1 Male & 0 & 22 & 55 & & & \\
\hline & 1.2 Female & 01 & 37 & 35 & & & \\
\hline \multirow{5}{*}{2.} & Age (in years): & & & & & 06 & $.01^{*}$ \\
\hline & $2.1 \quad 30-40$ & 0 & 02 & 11 & & & \\
\hline & $2.2 \quad 41-50$ & 0 & 07 & 29 & 17.78 & & \\
\hline & $2.3 \quad 51-60$ & 01 & 17 & 22 & & & \\
\hline & $2.4 \quad 61$ and above & 0 & 33 & 28 & & & \\
\hline \multirow{4}{*}{3.} & Religion: & & & & 1.77 & 04 & .77 \\
\hline & $3.1 \quad$ Hindu & 01 & 58 & 85 & & & \\
\hline & $3.2 \quad$ Sikh & 0 & 0 & 02 & & & \\
\hline & 3.3 Muslim & 0 & 01 & 03 & & & \\
\hline \multirow{5}{*}{4.} & Marital status: & & & & 11.13 & 06 & .08 \\
\hline & $4.1 \quad$ Unmarried & 0 & 01 & 03 & & & \\
\hline & $4.2 \quad$ Married & 01 & 43 & 81 & & & \\
\hline & 4.3 Divorced & 0 & 01 & 0 & & & \\
\hline & $4.4 \quad$ Widow/widower & 0 & 14 & 06 & & & \\
\hline \multirow{3}{*}{5.} & Area of residence: & & & & .382 & 02 & .82 \\
\hline & $5.1 \quad$ Rural & 01 & 44 & 66 & & & \\
\hline & 5.2 Urban & 0 & 15 & 24 & & & \\
\hline \multirow{5}{*}{6.} & Education: & & & & 29.32 & 06 & $.00^{*}$ \\
\hline & 6.1 Non-formal education & 01 & 17 & 05 & & & \\
\hline & 6.2 Primary & 0 & 17 & 15 & & & \\
\hline & 6.3 Higher secondary & 0 & 17 & 36 & & & \\
\hline & 6.4 Graduate and above & 0 & 08 & 34 & & & \\
\hline \multirow{6}{*}{7.} & Occupation status: & & & & 11.35 & 08 & .18 \\
\hline & 7.1 Government employee & 0 & 03 & 17 & & & \\
\hline & 7.2 Self employed & 0 & 08 & 18 & & & \\
\hline & 7.3 Private employee & 0 & 05 & 10 & & & \\
\hline & $7.4 \quad$ Home maker & 01 & 33 & 31 & & & \\
\hline & $7.5 \quad$ Retired & 0 & 10 & 14 & & & \\
\hline \multirow{5}{*}{8.} & Monthly income (in ₹): & & & & 12.46 & 06 & $.05^{*}$ \\
\hline & $8.1 \leq 10,000 /-$ & 0 & 14 & 09 & & & \\
\hline & $8.2 \quad 10,001-20,000 /-$ & 01 & 18 & 26 & & & \\
\hline & $8.3 \quad 20,001-30,000 /-$ & 0 & 12 & 12 & & & \\
\hline & $8.4 \geq 30,001 /-$ & 0 & 15 & 43 & & & \\
\hline \multirow{3}{*}{9.} & Type of family: & & & & .71 & 02 & .70 \\
\hline & 9.1 Joint family & 01 & 39 & 63 & & & \\
\hline & 9.2 Nuclear family & 0 & 20 & 27 & & & \\
\hline \multirow{4}{*}{10.} & Family history of diabetes & & & & & & \\
\hline & $\begin{array}{l}\text { mellitus: } \\
10.1 \text { No }\end{array}$ & 01 & 38 & 49 & \multirow{3}{*}{2.37} & \multirow{3}{*}{04} & \multirow{3}{*}{.66} \\
\hline & 10.2 Maternal & 0 & 11 & 24 & & & \\
\hline & 10.3 Paternal & 0 & 10 & 17 & & & \\
\hline
\end{tabular}




\begin{tabular}{|c|c|c|c|c|c|c|c|}
\hline \multirow{3}{*}{11.} & Dietary habit: & & & & 7.47 & 02 & $.02^{*}$ \\
\hline & 11.1 Vegetarian & 01 & 47 & 53 & & & \\
\hline & 11.2 Non- vegetarian & 0 & 12 & 37 & & & \\
\hline \multirow{4}{*}{12.} & Physical activity: & & & & 26.78 & 04 & $.00^{*}$ \\
\hline & 12.1 Light & 0 & 52 & 44 & & & \\
\hline & 12.2 Moderate & 01 & 05 & 41 & & & \\
\hline & 12.3 Heavy & 0 & 02 & 05 & & & \\
\hline \multirow{3}{*}{13.} & Do you have any other disease? & & & & & & \\
\hline & & 0 & 31 & 45 & 1.12 & 02 & .56 \\
\hline & $\begin{array}{cc}13.1 & \text { Yes } \\
13.2 & \text { No }\end{array}$ & 01 & 28 & 45 & & & \\
\hline \multirow{5}{*}{14.} & Treatment: & & & & 29.64 & 06 & $.00^{*}$ \\
\hline & 14.1 Oral hypoglycemic drugs & 0 & 55 & 77 & & & \\
\hline & 14.2 Insulin & 01 & 04 & 02 & & & \\
\hline & 14.3 Diet only & 0 & 0 & 09 & & & \\
\hline & 14.4 Others & 0 & 0 & 02 & & & \\
\hline
\end{tabular}

df: degree of freedom

significant $(*):(p \leq 0.05)$

Table 6 shows association of level of health-related quality of life among diabetic patients with the selected sociodemographic variables. As the result of chi $^{2}$ test, association of level of health-related quality of life with gender $\left(\chi^{2}=\right.$ $9.15, \mathrm{p}=.01)$, age (in years) $\left(\chi^{2}=17.78, \mathrm{p}=.01\right)$, education $\left(\chi^{2}\right.$ $=29.32, \mathrm{p}=.00)$, monthly income $\left(\chi^{2}=12.46, \mathrm{p}=.05\right)$, dietary habit $\left(\chi^{2}=7.47, \mathrm{p}=.02\right)$, physical activity $\left(\chi^{2}=26.78, \mathrm{p}=.00\right)$, treatment $\left(\chi^{2}=29.64, \mathrm{p}=.00\right)$ found significant at level of $\mathrm{p}$ $<0.05$. Hence, health-related quality of life is significantly associated with gender, age (in years), education, monthly income, dietary habit, physical activity and treatment.

\section{Discussion}

The findings of the study are discussed on the basis of objectives under following sections:

\section{Section 1 describes of the frequency distribution of socio-demographic variable}

Section 1 describes the socio-demographic variable and the results revealed that out of 150 samples, nearly half of the subjects, $(51.3 \%)$ were male, $(40.7 \%)$ in age group of 61 and above, (96\%) were Hindu, (83.3\%) were married, $(74 \%)$ were from rural area, $(35.3 \%)$ had secondary education, $(43.3 \%)$ were home maker, $(38.7 \%)$ had monthly income $\geq 30,001 /-,(68.7 \%)$ were from joint family, $(58.7 \%)$ had no family history of diabetes mellitus, $(67.3 \%)$ were vegetarian, $(64 \%)$ had light physical activity, $(50.7 \%)$ had other disease with diabetes mellitus, $(88 \%)$ were on oral hypoglycemic drugs.

Section 2 describes the frequency, percentage, median, range, standard deviation, standard error of mean of domains of health-related quality of life. In the present study results shown the overall mean and SD score of health-related quality of life among subjects i.e. mean score \pm S.D $136.69 \pm 26.343$ and overall health related quality of life with the mean percentage $68.34 \%$ (136.69). The study results revealed the overall health-related quality of life in which the most of subjects, $(60 \%)$ had good quality of life, $(39.3 \%)$ had average quality of life whereas only $(0.7 \%)$ had poor quality of life.

Section 3 describes the relationship between domains of health-related quality of life. In the present study, the relationship of role limitation with general health, physical limitation, symptom botherness, psychosocial satisfaction, economic worries, dietary satisfaction, treatment satisfaction/ follow up and personal belief was found moderate positive relationship $(p \leq 0.05)$. Hence, role limitation has impact on all the other domains of health related quality of life.

Section 4 describes the association of level of healthrelated quality of life among diabetic patients with the selected socio-demographic variables.

With view to determine association of level of health-related quality of life among diabetic patients with the selected socio-demographic variables, association was calculated by chi square test. The results revealed that the level of healthrelated quality of life among diabetic patients had significant association with gender, age (in years), education, monthly income, dietary habit, physical activity and treatment $(\mathrm{p} \leq 0.05)$.

\section{Conclusion}

Finding of the present study revealed that more than half of the subject had good health related quality of life with mean \pm S.D $136.69 \pm 26.343$. Mean percentage of overall health related quality of life was $(68.345 \%)$. The improvement in the role limitation will simultaneously improve all the domain of health-related quality of life which will helps to improve the overall quality of life. Health-related quality of life among diabetic patients had significant association with gender, age (in years), education, monthly income, dietary habit, physical activity and treatment. Adopting healthy life style and continuous treatment is necessary to maintain the good quality of life in diabetes. Hence, the present study concluded that high quality of life represents an ultimate goal and an important outcome of all medical interventions in diabetic patients.

\section{Recommendations}

Keeping in the view of present study findings, the following recommendations have been made:

- A similar study may be conducted on a large sample to validate and generalize the findings.

- Similar study can be conducted on different population of different culture and ethnic groups. A comparative study can be done on quality of life between rural and urban patients of Diabetes Mellitus.

- A true experimental study can be conducted to assess the quality of life of patients with diabetes mellitus. 


\section{References}

1. Park K. Text book of preventive and social Medicine. 23th edition. Bhanot Jabalpur Basarsidas 2015;341:389561.

2. World Health Organization. Global Report on Diabetes. Geneva [Internet]. 2016 [cited 2019 June 6]. Available from: https://www.who.int/diabetes/global-report/en/

3. World health organization. Diabetes factsheet. Geneva 2018. Available from: https://www.who.int/newsroom/fact-sheets/detail/diabetes.

4. International Diabetes Federation. IDF Diabetes Atlas. 8th edition. Brussels [Internet]. 2017 [cited 2019 June 19]. Available from: https://diabetesatlas.org/resources/2017atlas.html

5. Mustapha W, Hossain ZS, Loughlin KO. Management and Impact of Diabetes on Quality of Life among the Lebanese Community of Sydney: A Quantitative Study. J Diabetes Metabolism [ResearchGate]. 2014 [cited 2018;5(1):329. Available from: doi 10.4172/21556156.1000329

6. World Health Organization. The World Health Organization Quality of Life (WHOQOL)-BREF. WHO Geneva [Internet]. 2004 [cited 2018 May 22]. Available from: https://www.who.int/mental_health/media/68.pdf

7. Huang Chan I et al. Diabetes-Specific or Generic Measures for Health-Related Quality of Life? Evidence from Psychometric Validation of the D-39 and SF-36. International Society for Pharmacoeconomics and Outcomes Research (ISPOR) [Science direct.com, NCBI] 2008;11(3):450-461. Available from:

https://www.sciencedirect.com/science/article/pii/S109
8301510700139
Doi:
10.1111/j.15244733.2007.00261.x

8. Acharya LD et al. Development and validation of quality of life assessment instruments for diabetic patients. Asian Journal of Pharmaceutical and Health Sciences [Internet] 2014;4(4):1114-20. Available from: https://ajphs.com/journals/http_ajphs.abacieslogiciels. com_wpcontent_uploads_2015_01_04_AJPHS_OctDec_2014_6581.pdf

9. Bodh Anand. Himachal witnesses rise in diabetes cases especially in rural areas. Time of India [Internet] 2016. Available from: https://timesofindia.indiatimes.com/city/shimla/Himach al-witnesses-rise-in-diabetescases-especially-in-ruralareas/articleshow/52183194.cms

10. Al-Khawaldeh OA, Al-Hassan MA et al. Self-efficacy, self-management, and glycemic control in adults with type 2 diabetes mellitus. Journal of Diabetes Complications [science Direct.com] 2012;26:10-16. Available from: https://www.sciencedirect.com/science/article/abs/pii/S 1056872711001279?via\%3D ihub DOI: https://doi.org/10.1016/j.jdiacomp.2011.11.002

11. Nagpal Jitender et al. The Development of 'Quality of Life Instrument for Indian Diabetes Patients (QOLID): A Validation and Reliability Study in Middle- and Higher-Income Groups. JAPI [PubMed]. 2010 [cited 2018;58:295-305. Available from: http://www.japi.org/may_2010/Article_04.pdf

12. Kumar TK Ajesh, Chandran Soumya. Application of nursing theories. 1st edition. New Delhi. Jaypee publication 2017, 202-209. 